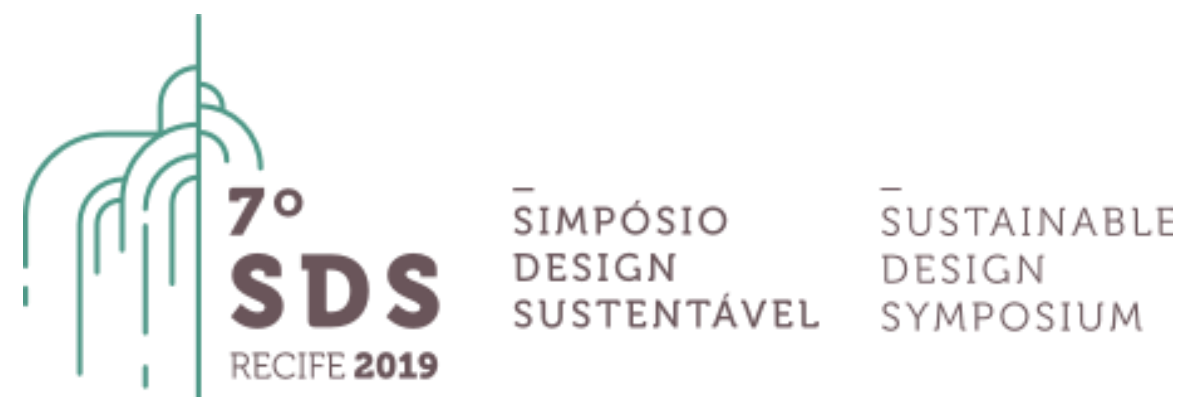

\title{
A Importância do Ativismo de Design no Processo de Difusão da Cultura da Sustentabilidade na Moda
}

\author{
Deise da Luz Santos ${ }^{1}$, Karine de Mello Freire ${ }^{2}$ \\ ${ }^{1}$ Universidade do Vale do Rio dos Sinos - UNISINOS, Mestre em Design, deiseluzz@gmail.com \\ ${ }^{2}$ Universidade do Vale do Rio dos Sinos - UNISINOS, Coordenadora do PPG Design, kmfreire@unisinos.br
}

\begin{abstract}
Resumo. Este estudo irá tratar da importância do ativismo de design como promotor de diálogos estratégicos capazes de promover mudanças sociais. Uma pesquisa-intervenção, realizada no Ecossistema da Moda Sustentável do RS, possibilitou o mapeamento dos processos de difusão da cultura da sustentabilidade na moda e identificou o ativismo de design realizado nas redes sociais da internet como um importante caminho dessa difusão. Para tanto, iremos elucidar sobre os tramas processuais que fazem do ativismo de design um condutor de inovação sociocultural na moda.
\end{abstract}

Palavras-chave. Design Estratégico, Ativismo de Design, Inovação Sociocultural, Moda Sustentável, Redes Sociais.

\section{Introdução}

O presente artigo explora o ativismo de design como modo de promover uma inovação sociocultural no sistema da moda, provocando rupturas nos modos pelos quais as pessoas acessam informação sobre produtos de moda. Que estratégias podem ser utilizadas para disseminar uma cultura de sustentabilidade?

A indústria têxtil impacta significativamente o planeta com a degradação de recursos naturais, em função da extração e utilização de matéria-prima para a confecção de roupas e acessórios. Confeç̧ões que são aceleradas no intuito de cumprir as agendas da moda pautadas pela concorrência de mercado, fazendo com que muitas pessoas tenham condições injustas de trabalho, como os locais impróprios e a carga horária aumentada em função da demanda. A falta de regras e leis mais acentuadas para garantir a decência e a transparência do setor é observada em diversos países. Acredita-se que uma mudança sistêmica para com essas questões pode proporcionar um desenvolvimento econômico mais sustentável, no viés do trabalho justo e respeito ao meio ambiente, atualizando o sistema atual instituído desde meados do século passado. Essas mudanças sistêmicas podem ser iniciadas pelo próprio tecido social através da recombinação de recursos capazes de promover diálogos estratégicos entre a sociedade. (FLETCHER; GROSE, 2011; MANZINI, 2008; 2017). 
Os movimentos sociais que partem de organizações comunitárias engajadas em descobrir formatos inovadores para solucionar problemas que não podem ser solucionados através dos padrões de organizações já existentes parecem ter as características necessárias para que o aprendizado e a inovação sociocultural aconteçam. A inovação sociocultural é iniciada de baixo para cima, ou seja, da própria sociedade, fazendo com que sejamos responsáveis pelas mudanças que queremos desenvolver, sem depender de outras instâncias para colocarmos em prática ações em prol dessas mudanças. Essas organizações costumam ser chamadas de organizações colaborativas e figuram como base das soluções para os problemas emergentes identificados nos diferentes níveis da vida em sociedade, como os enfrentados pela indústria da moda. (MANZINI, 2008).

Dentro do conceito de organizações colaborativas apresentado por Manzini (2008), encontramos uma abertura para o princípio dos ecossistemas criativos. Os ecossistemas criativos são entendidos como ambientes em que diferentes atores interagem entre si compartilhando um meio sociocultural. As características de um ecossistema criativo perpassam o desenvolvimento de processos criativos que resultam em dispositivos (artefatos, processos ou sistemas) possivelmente originais e inovadores. Essas características são possibilitadas pela natureza aberta dos ecossistemas, que demonstram a capacidade de manterem-se em equilíbrio entre a ordem e a desordem simultânea. (FRANZATO et al. 2015).

O ecossistema criativo do estudo em questão é o Ecossistema da Moda Sustentável do RS. Ele foi ativado por especialistas em design que operam por meio do Design Estratégico. A iniciativa nasceu da necessidade de gerar inovação e colaboração entre os atores da cadeia da moda gaúcha, sendo eles estilistas de marcas locais, pesquisadores, ativistas, institutos ligados à indústria da moda e comunidade. O Ecossistema trata-se de um projeto experimental que funciona através de ativações oportunas espalhadas pela cidade e através de um espaço físico para cursos, palestras, showroom e encontros colaborativos. (ECOSSISTEMA DA MODA SUSTENTÁVEL DO RS, 2019).

Esse estudo é parte dos resultados da pesquisa de mestrado da autora e apresenta um mapeamento dos processos de difusão da cultura da sustentabilidade na moda ativados pelo Ecossistema da Moda Sustentável do RS por meio da \#modamudamundo. Partimos do princípio de que o ativismo de design abre caminhos promissores para a transformação e inovação sociocultural através das ramificações do capital social. (FUAD-LUKE 2009). Ramificações que estão associadas ao capital institucional e cultural e movimentam-se nos eixos das orientações políticas, sociais e religiosas. Com suas habilidades de tornar as coisas visíveis e tangíveis, acreditamos que os especialistas em design possam mapear e catalisar iniciativas, operando por meio do ativismo, motivando, facilitando e acompanhando as mudanças. (FUAD-LUKE, 2009; MANZINI, 2017; ZURLO, 2010).

A cultura da sustentabilidade na moda perpassa o conceito de mentalidade lenta, proposto por Fletcher e Grose (2011). A mentalidade lenta está relacionada com a ressignificação dos seguintes valores: consumo, fartura, conveniência e identidade. Nesse sentido, aponta-se para um caminho em que a produção e o consumo serão mais refletidos e valorizados quando os indivíduos desfrutarem dessa mentalidade. Ela está relacionada também com a melhor apreciação e escolha de roupas por parte do consumidor, enaltecendo a qualidade em detrimento da quantidade e da rapidez com que consomem. Mas, além disso, e principalmente, aqui estamos tratando da mentalidade lenta atribuída a toda a cadeia da moda, em que todos os atores pertencentes como produtores, agricultores, comerciantes, designers, comunicadores, consumidores, entre outros, estejam alinhados com essa perspectiva, tratando-se de um movimento amplo, que gera consciência sobre os problemas causados pelo sistema atual e seus impactos. (FLETCHER; GROSE, 2011) 
Para tanto, serão agora discorridos sobre a Cultura da Sustentabilidade na Moda e Ativismo de Design nas Redes Sociais da Internet, construindo o embasamento necessário para a apresentação dos processos de ativismo mapeados no Ecossistema da Moda Sustentável do RS. Essa pesquisa tratou-se de uma pesquisa-intervenção inspirada na cartografia rizomática de Deleuze e Guattari (2011), guiada pelas pistas cartográficas de Passos, Kastrup e Escóssia (2015).

\section{Cultura da Sustentabilidade na Moda}

A mudança cultural rumo à sustentabilidade na cadeia da moda passa pelos três registros ecológicos indicados por Guattari (2001): o meio ambiente, as relações sociais e a subjetividade humana. É na esfera da subjetividade humana que a proposta de mentalidade lenta apresentada por Fletcher e Grose (2011) opera.

A degradação ambiental é observada ao longo de toda a cadeia de moda, desde a plantação e colheita da matéria prima até a logística de distribuição de roupas e acessórios circulantes no mundo, o que aumenta o consumo dos recursos naturais do planeta, como algodão, água e energia, gerando também um alto volume de lixo a partir do descarte indevido de resíduos. Resíduos que causam um impacto altamente significativo, mas que são negligenciados. No Brasil, menos de $10 \%$ do total de resíduos têxteis são reaproveitados na produção de outros produtos como barbantes, mantas, novas peças de roupas e fios, sendo os outros $90 \%$ descartados em aterros de lixo comum. Nesse sentido, observa-se a emergente mudança no processo de reciclagem desses resíduos, figurando como um dos principais problemas ambientais causados pela indústria da moda. (PINTO; SOUZA, 2015).

A mentalidade rápida, aqui chamada de fast fashion, é causadora da obsolescência programada de produtos de moda em função de suas dinâmicas e massivas coleções e tendências disseminadas para o público, gerando problemas sociais relacionados à moda. Para atender a agilidade que o mercado exige, o fast fashion faz com que todos os atores do sistema atribuam práticas insustentáveis às suas produções, forçando os recursos naturais, trabalhando com pequenas margens de lucro e gerando uma relação e uma cadeia competitiva negativa. Essa aceleração é também responsável pelos problemas sociais causados pela indústria, que para trabalhar rápido e com margens espremidas, opera em países sem legislações de trabalho estabelecidas, utilizando mão de obra barata, sem recursos, podendo muitas vezes ser comparada com trabalho análogo ao escravo. (FLETCHER; GROSE, 2011). A partir do lançamento da legislação progressiva e consciência social, a Europa vem praticando boas práticas relacionadas à produção de roupas, porém, países como China, Paquistão Bangladesh, Índia, Romênia, Turquia e Camboja, são produtores de moda rápida por não comportarem políticas para esse sistema, onde os donos das fábricas comprometem-se com seus clientes para entregar produtos em curto prazo, submetendo suas equipes a extensas horas de trabalho, em condições desumanas e com baixos salários. (PINTO; SOUZA, 2015).

Nesse caso, sugere-se que a sustentabilidade ambiental e social depende da subjetividade e da evolução do pensamento humano em relação ao consumo de moda. Nesse cenário, o consumo pode ser substituído pelo valor do cuidado, em que a lógica da roupa descartável é trocada pela conservação e manutenção das peças. A fartura pode ser entendida como a possibilidade de reciclar e reutilizar materiais, recombinando recursos para que novas peças sejam criadas a partir de resíduos e descartes. A conveniência pode relacionar-se com a colaboração e equilíbrio entre atores, organizações e marcas, abrindo espaço para uma economia mais colaborativa, baseada no conceito de troca. E a identidade, tão valorizada pelas pessoas no mundo da moda, subverter a lógica individualista e institui-se com o aumento dos relacionamentos ocorridos a partir dos demais valores. A ressignificação desses valores é entendida a partir do 
conceito de mentalidade lenta. A mentalidade lenta figura como evolução do sistema atual, passando do fast para o slow fashion. Nesse sentido, podemos entender que a cultura da sustentabilidade na moda tem como base a transformação da mentalidade através do aprendizado social, percorrendo o movimento slow fashion. (FLETCHER; GROSE, 2011).

\section{Ativismo de Design nas Redes Sociais da Internet}

A aproximação entre ativismo e design nasce a partir da concepção de que o ativismo, como propulsor de mudanças sociais, culturais e políticas, estimula o questionamento em relação ao futuro com a seguinte pergunta: em que tipo de sociedade nós queremos viver? E é nessa projetação de futuros que entra o pensamento de design, capaz de contribuir com caminhos responsáveis por causar o bem para a sociedade e para o planeta. Podendo, o ativismo de design, ser descrito da seguinte forma: "o ativismo de design é pensamento de design, imaginação e prática aplicada conscientemente ou inconscientemente para criar uma contra narrativa destinada a gerar e equilibrar mudanças sociais, institucionais, ambientais e / ou econômicas positivas". (FUAD-LUKE, 2009, p. 27, tradução nossa).

Ativistas de design podem, a partir de suas habilidades, projetar os caminhos futuros da sociedade e do planeta. Entendemos essa tarefa como necessária quando observamos as atuais agendas públicas em relação ao desenfreado desgaste de recursos sociais, ambientais e econômicos causados pelo fenômeno da globalização. São nessas esferas que existem possibilidades de mudança, possibilidades de introdução de um novo modo de ver e de viver o mundo, descontinuando sistemas estabelecidos em benefício de uma sociedade mais sustentável. Para Fuad-Luke (2009), o designer ativista pode interferir no funcionamento desses fluxos, e isso significa dizer que ele pode atuar promovendo mudanças culturais e sociais. . (FUAD-LUKE, 2009).

É nesse sentido que podemos identificar as redes sociais da internet como ferramentas de organização de encontros colaborativos aliadas ao ativismo. A rápida expansão da internet e tecnologias Web 2.0, que potencializaram a criação de sites, blogs, redes sociais e ferramentas de conversação em tempo real, possibilitam que mais pessoas sejam conhecedoras dos objetivos de um grupo ativista e optem por contribuir, tornando-se um ator envolvido com o projeto. Por parte dos designers ativistas, são canais que ampliam a comunicação e a coordenação de redes distribuídas de projeto. (FUAD-LUKE, 2009).

Para Recuero (2009), as interações sociais através das redes sociais da internet estão relacionadas com as percepções e motivações de cada pessoa, representando um processo sempre comunicacional entre o indivíduo e seus pares. Esse processo é denominado de interação relacional e pode ser considerado como o estabelecimento de laços dialógicos. Existem, também, as interações do tipo associativas, que acontecem quando indivíduos conectam-se pelo sentimento de pertencimento para com um determinado local, instituição ou grupo, caracterizando-se como um laço associativo. Os laços associativos são compreendidos como interações sociais reativas, mediadas pelo computador (Figura 1). 
Figura 1 - Tipos de Laços e Interações nas Redes Sociais

\begin{tabular}{|c|c|c|}
\hline Tipo de laço & Tipo de interação & Exemplo \\
\hline Laço associativo & Interaçāo reativa & $\begin{array}{c}\text { Decidir ser amigo de } \\
\text { lguém no Orkut, trocar } \\
\text { links com alguém no } \\
\text { Fotolog, etc. }\end{array}$ \\
\hline Laço dialógico & Interaçāo mútua & $\begin{array}{c}\text { Conversar com } \\
\text { alguém através do } \\
\text { MSN, trocar recados } \\
\text { no Orkut, etc. }\end{array}$ \\
\hline
\end{tabular}

Fonte: Recuero (2009, p.40).

Os laços sociais na internet também podem ser fortes ou fracos. Laços fortes são aqueles que se caracterizam pela intimidade, proximidade e intencionalidade de manter uma conexão entre pessoas. Já os laços fracos são percebidos por relações esparsas, que não traduzem proximidade e intimidade. (RECUERO, 2009). "Laços fortes constituem-se em vias mais amplas e concretas para as trocas sociais, enquanto os fracos possuem trocas mais difusas". (RECUERO, 2009, p. 41).

A intensidade dos laços sociais estabelecidos por meio das redes sociais da internet, parecem também influenciar no tipo e na intensidade do capital social gerado a partir desses vínculos. Vínculos fortes tendem a gerar capital social do tipo fortalecedor, estabelecendo trocas mais sólidas relacionadas aos valores percebidos e trabalhados pelo grupo, no sentido mais coletivo e institucional. Enquanto os vínculos fracos tendem a gerar capital social do tipo conectivo, que está relacionado com os valores primários que podem ser acessados pelo indivíduo, que reconhece esses valores (relacionais e normativos) e estabelece trocas iniciais a partir dessa identificação. As redes sociais, porém, oferecem, pelas suas características, a possibilidade de atribuir o valor da manutenção ao capital social. Esse valor está associado ao fato das redes sociais da internet serem utilizadas para manter contato. Essa característica pode aumentar o nível do capital social estabelecido e iniciar o processo de vínculos fortes entre diferentes atores e independentemente da localização e da distância desses atores. (RECUERO, 2009).

Porém, os laços fracos figuram como importantes componentes para a estrutura e equilíbrio dos sistemas estabelecidos através das redes sociais. São os laços fracos que conectam os grupos constituídos de laços fortes entre si, ou seja, conectam os clusters nas redes sociais. (MANZINI, 2017; RECUERO, 2009). Nesse sentido, podemos concluir que diálogos estratégicos capazes de provocar inovação sociocultural através do capital social, dependem do equilíbrio dos laços.

\section{Mapeamento de Processos: Ativistas como Promotoras de Diálogos Estratégicos}

Neste capítulo serão discorridos sobre a pesquisa-intervenção realizada para a observação de campo e sobre a trama Ativistas e Diálogos Estratégicos, desenhada a partir da pesquisa. 


\subsection{Pesquisa-intervenção}

Esta pesquisa se iniciou no mês de janeiro de 2018, através de encontros colaborativos ocorridos no Ecossistema da Moda Sustentável do RS que tiveram o intuito de traçar novas estratégias de ativações relacionadas à difusão da cultura da sustentabilidade na moda. A partir desses encontros colaborativos, algumas ideias de ativações foram desenhadas. Essas ideias, facilitadas pelas autoras e cocriadas em parceria com os demais atores do Ecossistema, foram projetadas para acontecerem na Virada Sustentável Porto Alegre 2018, Semana Fashion Revolution Porto Alegre 2018 e \#modamudamundo na rede social Instagram. A intervenção se deu a partir da distribuição dos artefatos projetados: combinação de texto (questionamento) e imagem (artística) elaborados em formato de postais. Esses postais foram criados por artistas locais contendo no verso o pedido para que as pessoas ativassem as suas redes através do uso das hashtags \#modamudamundo e \#quemfezminhasroupas, contando quais eram os seus modos de mudar a moda (Figura 2).

As respostas da sociedade para com o pedido foram nossa lente de pesquisa. A ideia foi que a \#modamudamundo pudesse servir de ponto de encontro e disseminação desses relatos. Ao longo do processo de pesquisa de campo, podemos perceber que a utilização da hashtag aconteceu de forma orgânica, sem que pudéssemos saber se as pessoas estavam ativando suas redes e utilizando as hashtags a partir do contato com os postais ou não. Esse fenômeno foi interpretado como positivo, pois o objetivo principal, que é contribuir com a difusão da cultura da sustentabilidade na moda, parece estar sendo cumprido a partir da disseminação e engajamento orgânicos observados.

A observação dos processos de difusão, possibilitado a partir do acompanhamento da hashtag, contou com a utilização do hipertexto como ferramenta de navegação. Isso significa que a pesquisa cartográfica foi potencializada por essa possibilidade de seguir rastros, de entender o território da \#modamudamundo mais extenso do que suas próprias publicações, ampliando o espaço de observação para os diferentes caminhos digitais percorridos. É nessa perspectiva que tivemos a hashtag como ponto de partida para nossa observação, servindo como norte para a explicitação de tramas construídas coletivamente pelos atores do Ecossistema e pelas demais pessoas que tiveram contato com nossas ativações.

Nesse estudo, vamos apresentar a trama que conecta as ativistas com os diálogos estratégicos capazes de difundir a cultura da sustentabilidade na moda. Ativistas que foram identificadas a partir de seus registros com a \#modamudamundo ao longo do ano de 2018. 
Figura 2 - Exemplo de Artefato Projetado (Postal) pelo Ecossistema da Moda Sustentável do RS
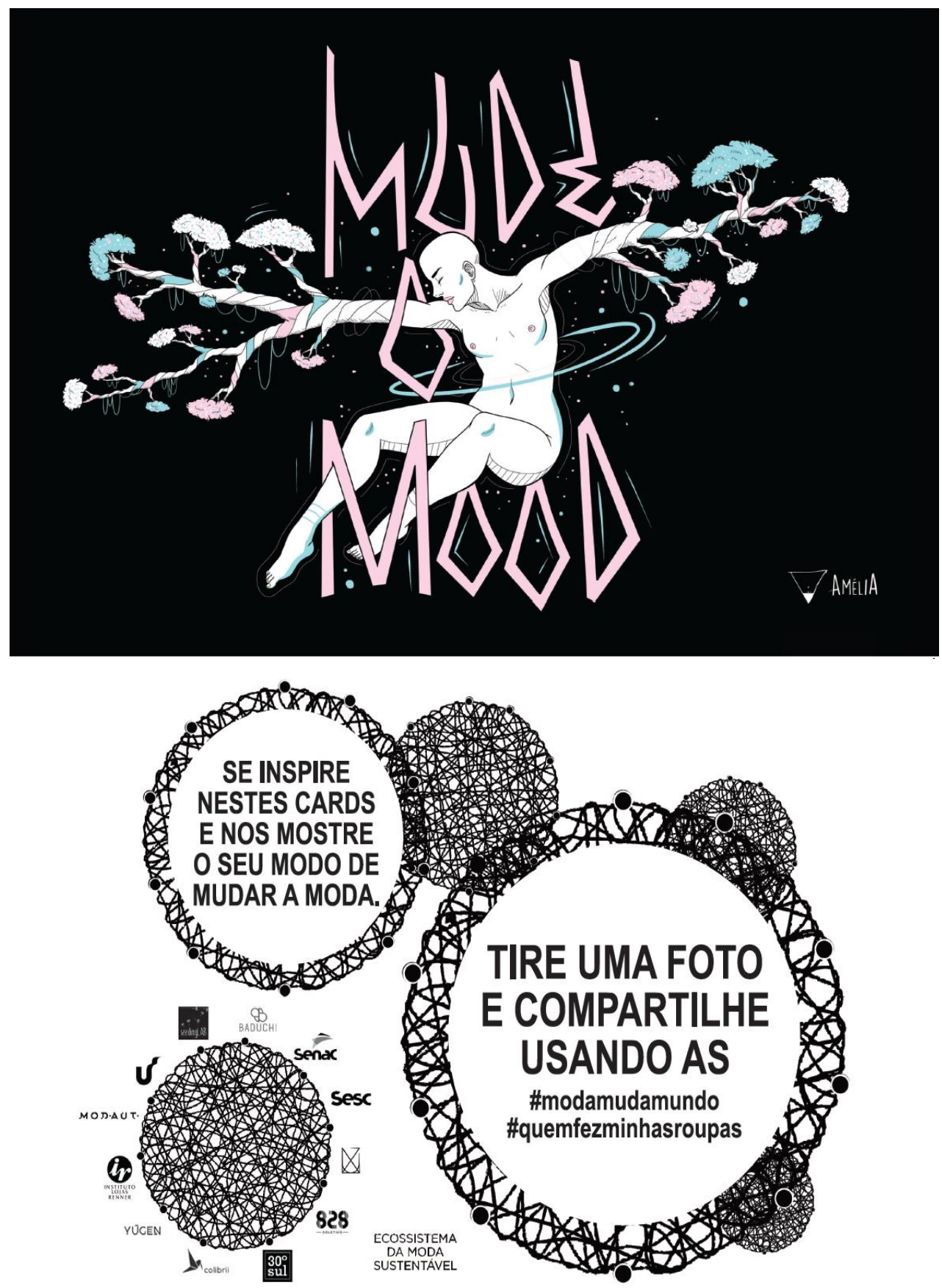

Fonte: Frente elaborada pela artista Renata Duarte do Coletivo Amélia e verso elaborado pelos atores do Ecossistema da Moda Sustentável do RS

\subsection{Ativistas e Diálogos Estratégicos}

Ao longo de nosso estudo cartográfico, podemos perceber a importância do papel de ativistas da moda sustentável na promoção de diálogos estratégicos. O papel de ativistas parece estar associado ao que Guattari (2001) chama de subjetividade humana. A subjetividade humana é um dos três registros ecológicos necessários para a sustentabilidade, sendo o meio ambiente e as relações sociais os demais registros. A subjetividade humana está relacionada com a capacidade do ser humano em elevar genuinamente a consciência sobre sua própria visão de mundo. Acreditamos que, através da explicitação de suas subjetividades, pessoas com características e 
habilidades ativistas possam contribuir com a conscientização de outras pessoas. Essa contribuição é importante por possibilitar a abertura de novos diálogos. Acreditamos, também, que o ativismo de design seja um caminho fértil para que estratégias de diálogos sejam traçadas e disseminadas. Considerando que o papel de ativistas de design é operar em sociedade, através de instrumentos naturais da atividade de design capazes de inferir na qualidade e aceitabilidade de novas projeções, a recombinação de recursos existentes serve como meio de propagação de contra narrativas, capazes de gerar e equilibrar as mudanças em prol de uma sociedade sustentável. (FUAD-LUKE, 2009).

As ativistas observadas através da \#modamudamundo (Figura 3), estão conectadas com o Ecosssistema da Moda Sustentável do RS, pois participaram de ativações do Ecossistema espalhadas pela cidade e tiveram contato com os artefatos projetados. Porém, podemos notar que suas ativações com a \#modamudamundo aconteceram de forma orgânica. Isso significa dizer que as ativações aconteceram nos dias de intervenção de campo motivadas por nossa ação, mas não apenas neles, sendo uma prática constante das ativistas ao longo do ano de 2018. Podemos notar a recombinação de recursos como importante estratégia de diálogo social. Dispositivos relacionais como a vestimenta, os diálogos possibilitados pelos espaços de fala e o uso de hashtags, podem ser considerados a tríade de recursos capaz de promover diálogos estratégicos em prol das mudanças.

O ativismo vem de dentro, do desejo de transformar o status quo de uma situação, de transmitir uma visão de mundo através de narrativas e ações. A vestimenta, nesse contexto, é símbolo de discurso e de exemplo. Na Figura (3a), a especialista em design e ativista Cacá Camargo, aparece utilizando roupas das marcas Wendyel Borin, Real Envido e Yugen. Marcas locais, situadas na cidade de Porto Alegre, e sustentáveis. Wendyel Borin produziu a saia assimétrica utilizada pela ativista, posicionando-se como uma marca de alfaiataria descontruída com o propósito de ressignificar a moda. A Real Envido, uma marca eco e slow fashion, presa pela moda brasileira e tem como propósito a concepção de um futuro mais sustentável em relação à moda. Já a Yugen, promove a ideia de livre experimentação através do vestuário. Marcas locais, que prezam pela qualidade das peças, pela mão de obra justa e principalmente pelo propósito através da moda. A ativista em questão, além de representar seu posicionamento em relaçao à moda sustentável através da roupa, ocupa espaços de fala importantes como instiuições de ensino e eventos de moda sustentável, mantendo as redes sociais da internet como parte de sua comunicação diária. A utilização das hashtags de forma combinada acontece para que suas causas e seus conceitos possam ser entendidos na sua plenitude. Podemos notar essa manifestação através das publicações (Figuras $3 b$ e $3 c$ ), em que a ativista anuncia os eventos em que está participando e ao mesmo tempo utiliza as hashtags \#quemfezminhasroupas, \#modamudamundo, \#fashionrevolution, \#fashrevpoa e \#slowfashion. Podemos também notar que laços dialógicos são estabelecidos através das publicações (Figuras 3a, 3b e 3c) em que a ativista destaca os nomes de quem ela está relacionando-se através do recurso @ no Instagram. Esse recurso permite que o usuário da rede social possa marcar outro usuário que será notificado assim que a marcação acontecer. Esses laços dialógicos podem indicar a promoção de vínclulos fortes através das redes sociais.

Durante as eleições de 2018, ativistas do Ecossistema foram às ruas (Figura 3d), levando mensagens e posicionamentos políticos para compartilhar com a sociedade através da campanha Vote Nelas. Ambientes em que a cultura da sustentabilidade na moda esteve presente, sendo representada e tangibilizada através de diferentes ações. A ação mais expressiva foi a colaboração ocorrida para o desenvolvimento de ecobags e lenços ativistas, que foram distribuídos e utilizados como forma de protesto nas semanas que antecederam as eleições (Figura 3e). A colaboração em torno da criação e produção dos lenços e das ecobags pode ser considerada benéfica por 
promover o conhecimento entre as pessoas, que em um ambiente de produção conjunta podem trocar experiências e unirem-se por uma causa maior. Dessa forma, a geração de sentido acontece de duas formas: pelo uso dos acessórios produzidos com o reaproveitamento de resíduos têxteis e pela movimentação realizada para a produção dos mesmos, aproximando e exercendo o valor da troca de conhecimento entre os atores envolvidos. É possível notar que o diálogo da ativista perpassa um espaço de fala significativo, posicionando a moda sustentável como atividade política. Podemos perceber essa intenção através da combinação de hashtags utilizadas por Liege (Figuras 3d, 3e e 3f): \#modamudamundo, \#mulheresnopoder \#votenelas.

Outra provocação foi iniciada por Carina Brendler, designer de moda que criou o seu próprio Ateliê focado na recuperação de vestidos usados em momentos de celebração, como casamento, formatura, début e demais rituais. Carina é entusiasta da moda sustentável e conectou-se com o Ecossistema desde a sua criação, acompanhou alguns encontros e abraçou a ideia da \#modamudamundo após ter contato com os postais através das nossas ativações, utilizando-a em suas publicações como forma de tornar visível a sua manifestação. A motivação é conscientizar as mulheres sobre moda sustentável através de uma linguagem que considera os rituais de celebração como ponto central no processo de conscientização. Mulheres que não fazem parte do universo da indústria da moda e que por vezes acabam tendo o seu primeiro contato com uma possibilidade de recuperação e reutilização de peças através desses rituais (Figuras $3 \mathrm{j}, 3 \mathrm{k}, 3 \mathrm{l}, 3 \mathrm{~m}$ ). Carina circula por diferentes eventos de moda sustentável e tem bastante representatividade no cenário da moda gaúcha, obtendo 4.500 seguidores no Instagram. Sua principal contribuição é a combinação de hashtags capaz de levar a cultura da sustentabilidade na moda para diferentes mulheres. Como exemplo, podemos citar as hashtags \#modamudamundo, \#upcycle, \#ecosexy e \#vestidodeformatura, que são combinações utilizadas pela ativista em uma mesma publicação.

Acreditamos que o modo de operar dessas ativistas favoreça a difusão da cultura da sustentabilidade na moda através da recombinação de recursos necessários para que o diálogo chegue até as pessoas que estão fora do universo da moda. A utilização de recursos capazes de dialogar com diferentes grupos parece ampliar as relações sociais, através de conexões que geram vínculos para com o Ecossistema. É o caso da \#modamudamundo e dos textos e imagens que as acompanham. É possível perceber nas publicações (Figura 3), que as ativistas em questão unem temáticas do seu interesse através das hashtags, Cacá Camargo é ativista do Movimento Fashion Revolution, Liege Massi percorre territórios capazes de posicionar a moda como política e Carina Brendler promove diálogos planejados para conversar com diferentes perfis de mulheres.

Como principal contribuição dessa trama, consideramos que a recombinação de recursos estabelecida através de dispositivos relacionais torna a cultura da sustentabilidade na moda mais difusa, alcançando públicos de fora do universo do design de moda e chegando até diferentes pessoas que passam a tomar conhecimento e consciência sobre os probelmas causados pela indústria, bem como possibilidades de mudança. A recombinação de recursos promove o capital social através do aprendizado possibilitado pelo ativismo de design. (FUAD-LUKE, 2009; HIGGINS, 2005; MANZINI, 2008, 2017). A representação através da vestimenta e os espaços de fala percorridos pelas ativistas, juntamente com o uso das redes sociais da internet como ferramenta de comunicação, formam a tríade necessária para que a difusão aconteça. Baseado nos princípios de Recuero (2009), acreditamos que a junção de diferentes hashtags possibilita o surgimento de novos laços sociais originados pelos diferentes interesses pessoais. O surgimento de novos laços sociais é o propulsor da difusão da cultura. 
Figura 3 - Ativistas e Diálogos Estratégicos
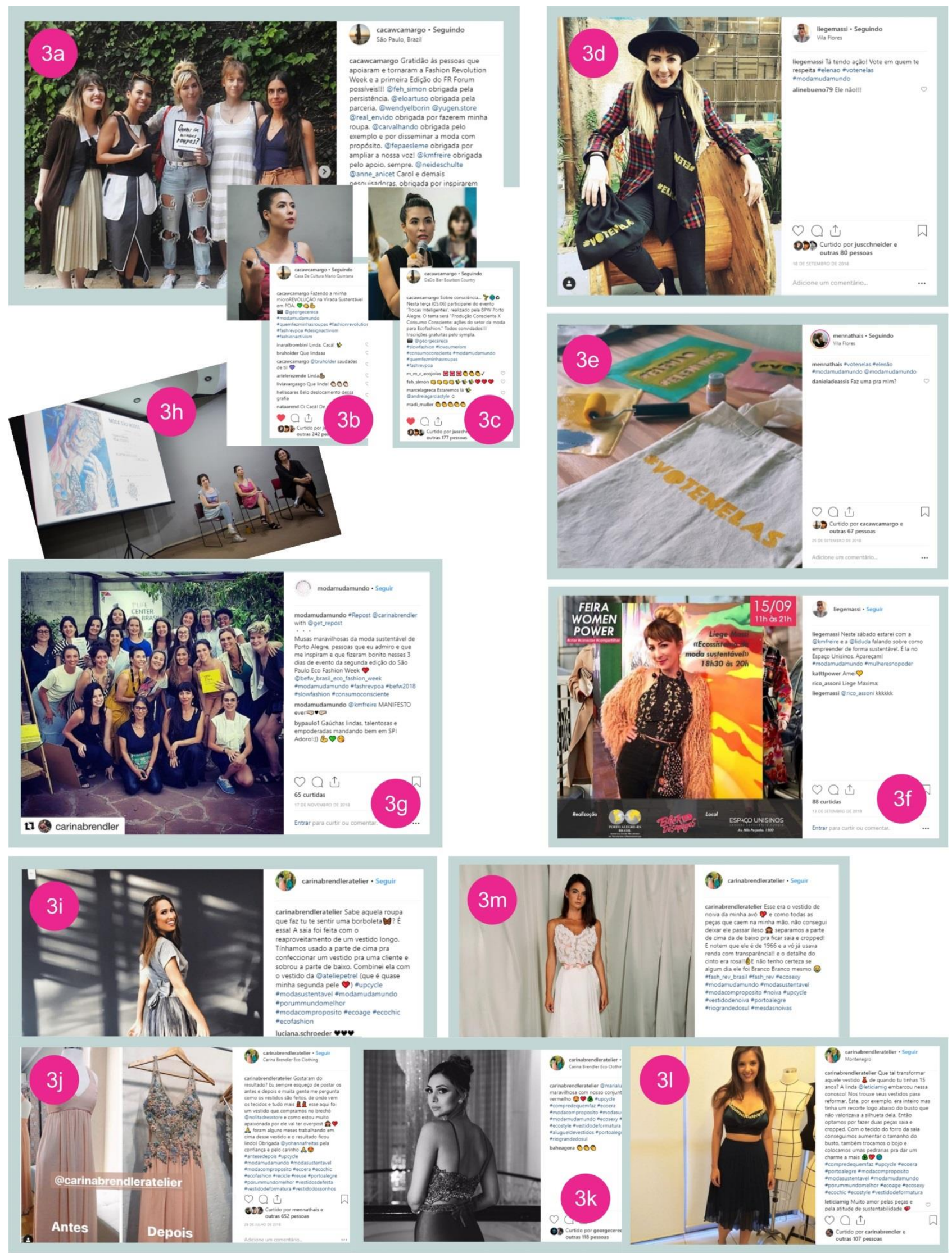

Fonte: Elaborada pela autora com base nas publicações feitas com a \#modamudamundo (2019). 


\section{Conclusão}

Esse artigo apresentou um recorte das tramas de difusão da cultura da sustentabilidade na moda no Ecossistema da Moda Sustentável do RS. Esse recorte é parte dos resultados de pesquisa de mestrado da autora. Através de uma pesquisa-intervenção baseada nos princípios da cartografia, encontramos diferentes tramas processuais. Uma delas é a trama das ativistas de design como promotoras de diálogos estratégicos.

A partir da observação das ativações realizadas com a \#modamudamundo, percebemos a importância do papel das ativistas de design e de moda sustentável no processo de difusão da cultura. É através da recombinação de recursos existentes que o papel das ativistas é reconhecido como importante promotor de diálogos estratégicos capazes de gerar consciência social sobre os problemas emergentes da moda. A recombinação de recursos está relacionada com a habilidade das ativistas para tornar visíveis e tangíveis as temáticas emergentes, perpassando as seguintes questões: a representação através da vestimenta, os espaços de fala como promotores de diálogos e o uso de hashtags combinadas capazes de promover um maior alcance para os diálogos ampliando as relações sociais.

Nosso intuito com esse estudo é estimular que novas ativações do Ecossistema e de outros coletivos aconteçam e que considerem as ativistas e suas habilidades com recombinação de recursos para que novos diálogos estratégicos sejam estabelecidos, contribuindo com processo de inovação sociocultural.

\section{Referências}

ECOSSISTEMA DA MODA SUSTENTÁVEL DO RS. Quem Somos. Porto Alegre, 2018. Disponível em: <https://modamudamundo.cc/sobre/>. Acesso em: 29 abr. 2019.

FLETCHER, K; GROSE, L. Moda e sustentabilidade: design para mudança. São Paulo: Senac São Paulo, 2011.

FRANZATO, C. et al. Inovação cultural e social: design estratégico e ecossistemas criativos. In: FREIRE, K. (Org.). Design Estratégico para a Inovação Social e Cultural. São Paulo: Kazuá, 2015. p. 157-182.

FUAD-LUKE, A. Design activism: beautiful strangeness for a sustainable world. London: Earthscan, 2009.

GUATTARI, F. As três ecologias. 11. ed. Campinas: Papirus, 2001.

HIGGINS, S. Fundamentos Teóricos do Capital Social. Chapecó: Argos Ed. Universitária, 2005.

MANZINI, E. Design para a inovação social e sustentabilidade: comunidades criativas, organizações colaborativas e novas redes projetuais. Rio de Janeiro: E-papers, 2008.

MANZINI, E. Design quando todos fazem design: uma introdução ao design para a inovação social. São Leopoldo: Editora Unisinos, 2017.

MODAMUDAMUNDO. [Hashtag \#modamudamundo]. Menlo Park, 14 jan. 2017. Instagram: \#modamudamundo. Disponível em: https://www.instagram.com/explore/tags/modamudamundo/>. Acesso em: 10 jan. 2019. 
PASSOS, E; KASTRUP, V; ESCÓSSIA, L. Pistas do método da cartografia. Pesquisa intervenção e produção de subjetividade. Porto Alegre: Sulina, 2015.

PINTO, A; SOUZA, C. Roupas feitas de roupas. Revista Iniciação. Edição temática em sustentabilidade. v.5, n. 3. São Paulo: Centro Universitário Senac, 2015.

RECUERO, R. Redes sociais na internet. Porto Alegre: Sulina, 2009.

ZURLO, F. Design Strategico. In: XXI Secolo, vol. IV, Gli spazi e le arti. Roma: Enciclopedia Treccani, 2010. 